\title{
Combined and single effects of pesticide carbaryl and toxic Microcystis aeruginosa on the life history of Daphnia pulicaria
}

\author{
S. Cerbin • M. H. S. Kraak $\cdot$ P. de Voogt $•$ \\ P. M. Visser $\cdot$ E. Van Donk
}

Published online: 27 February 2010

(C) The Author(s) 2010. This article is published with open access at Springerlink.com

\begin{abstract}
The combined influence of a pesticide (carbaryl) and a cyanotoxin (microcystin LR) on the life history of Daphnia pulicaria was investigated. At
\end{abstract}

Guest editors: M. Silva-Briano \& S. S. S. Sarma / Biology of Cladocera (Crustacea): Proceedings of the VIII International Cladocera Symposium

S. Cerbin · E. Van Donk

Netherlands Institute of Ecology (NIOO-KNAW), Rijksstraatweg 6, 3631 AC Nieuwersluis,

The Netherlands

P. M. Visser

Department of Aquatic Microbiology, IBED,

University of Amsterdam, Nieuwe Achtergracht 127,

1018 WS Amsterdam, The Netherlands

P. de Voogt

Department of Earth Surface Processes and Materials, IBED, University of Amsterdam, Amsterdam,

The Netherlands

M. H. S. Kraak

Department of Aquatic Ecology and Ecotoxicology, IBED, University of Amsterdam, Amsterdam,

The Netherlands

S. Cerbin $(\square)$

Department of Hydrobiology, Faculty of Biology,

Adam Mickiewicz University, ul. Umultowska 89,

61-614 Poznan, Poland

e-mail: cerbins@amu.edu.pl the beginning of the experiments animals were pulse exposed to carbaryl for $24 \mathrm{~h}$ and microcystins were delivered bound in Microcystis' cells at different, sub-lethal concentrations (chronic exposure). In order to determine the actual carbaryl concentrations in the water LC-MS/MS was used. For analyses of the cyanotoxin concentration in Daphnia's body enzymelinked immunosorbent assay (ELISA) was used. Individual daphnids were cultured in a flow-through system under constant light $(16 \mathrm{~h}$ of light: $8 \mathrm{~h}$ of dark), temperature $\left(20^{\circ} \mathrm{C}\right)$, and food conditions (Scenedesmus obliquus, $1 \mathrm{mg}$ of $\mathrm{C}^{-1}$ ). The results showed that in the treatments with carbaryl egg numbers per female did not differ significantly from controls, but the mortality of newborns increased significantly. Increasing microcystin concentrations significantly delayed maturation, reduced size at first reproduction, number of eggs, and newborns. The interaction between carbaryl and Microcystis was highly significant. Animals matured later and at a smaller size than in controls. The number of eggs per female was reduced as well. Moreover, combined stressors caused frequent premature delivery of offspring with body deformations such as dented carapax or an undeveloped heart. This effect is concluded to be synergistic and could not be predicted from the effects of the single stressors.

Keywords Daphnia - Pesticides - Cyanobacteria · Microcystin LR · Multiple stressors ·

Synergistic effects 


\section{Introduction}

Zooplankton plays an important role in aquatic food webs and it is crucial to know how man-made and natural toxicants, such as cyanobacterial toxins, affect their population dynamics and life history. Due to increasing agricultural intensive land use with pesticide spray drift or drain flow, the zooplankton is confronted with pesticides in the water. These may be episodic events exposing zooplankton to short-term pulse concentrations of pesticides (Liess et al., 1999). However, zooplankton is continuously exposed to natural toxins (microcystins) produced by cyanobacteria that are often dominating during summer in over-fertilized lakes (Sondergaard \& Jeppesen, 2007). Analysis of joint effects of pesticides and cyanotoxins on species and communities is critical for a full understanding of the risks to the environment and humans.

Cyanobacteria have become an increasing problem in aquatic ecosystems due to bloom formation and toxin production (Chorus \& Bartram, 1999). They dominate many eutrophic aquatic ecosystems due to rising nutrient loading, water temperatures, duration of summer stratification, increased water residence time, and salination (Paerl \& Huisman, 2008). Cyanobacteria and their toxins have been shown to lower zooplankton performance such as feeding, growth rates, reproduction, and longevity (e.g., DeMott et al., 1991, Rohrlack et al., 2004, Von Elert, 2004). One of the most commonly occurring cyanotoxin is microcystin LR produced by many cyanobacterial species, e.g., Microcystis aeruginosa (Sivonen \& Jones, 1999). Hietala et al. (1997) have shown that longevity, growth, and reproduction of Daphnia were negatively affected by toxic Microcystis cells. Moreover, microcystin LR containing cells caused a dramatic reduction in growth and resulted in death of the animals (Lürling, 2003).

Pesticides are widely produced and released into the environment. They can be harmful to zooplankton, especially to Daphnia (e.g., Helgen et al., 1988). Insecticides such as carbamates and organophosphates applied in sub-lethal doses can induce the development of protuberant structures in Daphnia; such structures are reported to have originally evolved as a response to predator kairomones (Hanazato, 1991). Havens (1995) exposed natural plankton communities enclosed in mesocosms to the carbamate insecticide carbaryl and observed that Daphnia were the most sensitive to the insecticide. The elimination of Daphnia from the zooplankton led to an increase in algal biomass. Hanazato \& Dodson (1995) found synergistic effects of carbaryl, predator kairomone, and low oxygen concentrations. These effects reduced juvenile growth rate and size at maturation and caused smaller clutch and neonate sizes. The authors stated that one factor reduced tolerance to the other factors. This underlines the importance of assessing the joint effects of multiple stressors, which cannot be predicted by summing up simple effects (Sih et al., 1998; Vinebrooke et al., 2004). Hence, there is an urgent need to develop a better understanding of the interactive effects of multiple stressors on species and communities to better predict their responses to the changing environment.

The aim of this study was therefore to assess the joint effects on daphnids of a pesticide and a cyanotoxin, which can occur simultaneously in environment and may potentially result in a complex interactive effects. We formulated the hypothesis that withstanding of a long term stress caused by a cyanotoxin can be disturbed even by the short term influence of another stressor such as a pulse exposure to a pesticide. Even sub-lethal doses of a pesticide, when applied in combination with a microcystin will cause Daphnia to reduce the size at maturity, which will also be delayed and will have less offspring than individuals exposed to only a single stressor. In order to test our hypothesis, we conducted life history experiments on D. pulicaria by exposing the animals to two stressors; the pesticide carbaryl and the cyanotoxin microcystin LR within Microcystis cells, both individually and together.

\section{Materials and methods}

\section{Daphnia pulicaria}

Prior to the start of the experiments, animals of a single clone of Daphnia pulicaria Forbes 1893 (isolated from the mesotrophic lake Maarsseveen, the Netherlands) were adapted to laboratory conditions. Animals were fed the chlorophyte Scenedesmus obliquus (Turpin) Kützing at a concentration of $1.0 \mathrm{mg} \mathrm{C} 1^{-1}$. The flow-through culture system with $140 \mathrm{ml}$ flasks was used in preculture and in 
experiments (Doksaeter \& Vijverberg, 2001; Hulsmann et al., 2004). We used the offspring from the fourth clutch $(<24$-h-old) of females grown for three generations under the same conditions as during experiments. All experiments were conducted in rooms with controlled light ( $16 \mathrm{~h}$ of light: $8 \mathrm{~h}$ of dark) and temperature $\left(20^{\circ} \mathrm{C}\right)$ and daphnids were kept in artificial ADaM media (Kluttgen et al., 1994).

\section{Algae}

The chlorophyte $S$. obliquus was used in all experiments as the main food source. It was maintained in 1.0-1 chemostat systems in continuous light of $120 \mu \mathrm{mol}$ photons $\mathrm{s}^{-1} \mathrm{~m}^{-2}$ at $20^{\circ} \mathrm{C}$ on $\mathrm{WC}$ medium (Guillard \& Lorenzen, 1972) and with a dilution rate of $0.8-1$ per day. The algae growing in single cells were kept at exponential growth phase. Prior to feeding, the algal suspension was centrifuged to concentrate and separate cells from the medium. The medium was discarded and cells of Scenedesmus resuspended in ADaM media. Approximately 300,000 cells of Scenedesmus per ml equaled to $1 \mathrm{mg} \mathrm{C}^{-1}$.

Carbaryl

The pesticide Carbaryl Pestanal ${ }^{\circledR}$ (1-naphthyl methylcarbamate) was used in the experiments (CAS\#: 63-25-2). The pure chemical was obtained from Riedel-de-Haën (Analytical standard, HPLC 99.8\% area). A stock solution of carbaryl was prepared by dissolving $100 \mathrm{mg}$ of carbaryl in methanol (Biosolve, Methanol absolute ULC/MS). Standard solutions of subsequent concentrations were obtained by diluting the stock solution in pure methanol. All chemicals were stored in a refrigerator at $4^{\circ} \mathrm{C}$. In order to achieve required carbaryl concentrations during the experiments $100 \mu \mathrm{l}$ of respective standard solutions were added to 11 of media. Water samples for chemical analyses of carbaryl were preserved with formic acid and analyzed the same day. A LC-MS/MS [4000 QTrap (Applied Biosystems) operated with electrospray ionization in the positive ion mode (ESI)] was used for the determination of the actual concentrations of the pesticide. The separation was done on the column Pathfinder (Shimadzu): $4.6 \times 50 \mathrm{~mm}$, silica $3003.5 \mu$ C18 (part no: 920-120601-11, Column no: 2006040, batch: B300-62). The eluents were (A) pure methanol (Biosolve) and (B) sub-boiled water, both with $5 \mathrm{mmol}$ of $\mathrm{NH}_{4}$ Ac. The total flow rate of eluent $\mathrm{A}$ and $\mathrm{B}$ was $0.4 \mathrm{ml} \mathrm{min}^{-1}$. The initial gradient was $100 \% \mathrm{~B}$, decreasing to $0 \%$ after $4 \mathrm{~min}$. The total run time was $8 \mathrm{~min}$. The transitions $202>145$ and $202>127$ were monitored. The cone voltage and the collision energy were optimized for carbaryl at 12 and $32 \mathrm{eV}$, respectively.

\section{Microcystin}

Microcystin LR was added in the experiments as particulate microcystin LR bound in cells of Microcystis aeruginosa Kützing, PCC7806. Microcystis strain PCC7806 is known to produce only two kinds of hepatotoxins: $\left[\mathrm{Asp}^{3}\right]$ microcystin-LR and microcystinLR (Tonk et al., 2009), further referred to as microcystin-LR. M. aeruginosa was cultured on WC media in chemostats at continuous light $(100 \mu \mathrm{mol}$ photons $\left.\mathrm{s}^{-1} \mathrm{~m}^{-2}\right)$ and temperature $\left(22^{\circ} \mathrm{C}\right)$. The dilution rate of media was 0.81 per day. In order to separate cells from the medium the same procedure as for Scenedesmus was applied.

At the end of experiments daphnids were taken for determination of the microcystin concentration. Single animals were placed in Microcystis free media with Scenedesmus added to feed for $2 \mathrm{~h}$ to allow the animals to defecate microcytin containing cells from the guts. This was done because ingested Microcystis cells could result in measuring microcystin in the guts but not absorbed in the tissues, leading to an overestimating of the microcystin actually assimilated.

In order to measure microcystin concentrations in daphnids' body we extracted the animal in $75 \%$ methanol, using three extraction rounds as described in Fastner et al. (1998), with an additional step for destructing tissues in a Mini Bead Beater (BioSpec Products Inc., Bartlesville, Oklahoma, USA) with $0.5 \mathrm{~mm}$ silica beads (Tonk et al., 2005). The extracts were dried by blowing them with $\mathrm{N}_{2}$ at $40^{\circ} \mathrm{C}$ and then redissolved in $150 \mu \mathrm{l}$ of $5 \%$ methanol. This final solution was analyzed using the ELISA (enzymelinked immunosorbent assay, Envirologix QuantiPlate Kit for Microcystin), according to the protocol with increased sensitivity.

\section{Experiments}

We performed three laboratory experiments, each with five replicates per treatment; (1) with the 
pesticide carbaryl only, (2) with Microcystis cells only, and (3) with both carbaryl and Microcystis cells combined. The purpose of experiments (1) and (2) was to test the reaction of Daphnia to a single stressor and also "tune up" the experiment with the combined stressors.

In the first experiment, individual daphnids in a tube were exposed to carbaryl for $24 \mathrm{~h}$ (pulse exposure). The animals were not fed during the exposure period to avoid binding of the pesticide to food particles, because such a complexation could have increased the effective concentration during the experiments. After $24 \mathrm{~h}$ all animals were transferred to a flow-through system. From then on daphnids were fed with $S$. obliquus $\left(1 \mathrm{mg} \mathrm{C} \mathrm{l}^{-1}\right)$. The animals in the controls went through the same procedure, but without carbaryl. At the beginning and after $24 \mathrm{~h}$ exposure period, water in the experimental as well as control tubes, was sampled for carbaryl determinations. There were five different concentrations of carbaryl and each of them replicated five times. The measured concentrations in the pesticide treatments are shown in Table 1 . None of the controls were contaminated with carbaryl.

In the second experiment, daphnids were fed Scenedesmus with addition of Microcystis cells in treatments testing the influence of cyanotoxins. At the beginning of the experiment all animals were starved for $24 \mathrm{~h}$, like in experiment (1). Then the animals received equal concentrations of Scenedesmus; ca. 300,000 cells ml ${ }^{-1}\left(1 \mathrm{mg} \mathrm{C}^{-1}\right)$. The controls were fed only Scenedesmus and the Microcystis treatments (M) comprised different percentages of Microcystis cells in total food particles: 3\% (M1), 5\% (M2), 10\% (M3), 15\% (M4), and 20\% (M5) (Table 1). There were single daphnids in every tube and each treatment was replicated five times.

In the third experiment, we combined the design of experiment (1) and (2), and daphnids were exposed to carbaryl only (P), Microcystis only (M), and combination of both (MP). At the beginning of the experiment animals were split into two groups. Individuals from first group were placed in clean ADaM media and later (after $24 \mathrm{~h}$ ) this group was divided again into controls (five replicates) and Microcystis treatments (five levels $\times$ five replicates). Individuals from the second group were exposed to carbaryl (pulse exposure for $24 \mathrm{~h}$ ) and later this group was divided into carbaryl treatment (five levels $\times$ five replicates) and carbaryl + Microcystis treatment (five levels $\times$ five replicates). This set up required 80 animals in total and they were placed individually in the tubes. After the pulse exposure (24 h) all animals were transferred to a flow-through system. From then on daphnids in controls and carbaryl treatments were fed with $S$. obliquus only, in Microcystis treatment and Microcystis + carbaryl treatment with $S$. obliquus $+M$. aeruginosa (Table 1). The concentrations of Microcystis were scaled down, based on the results from experiment (2). The same concentrations of the pesticide were used in carbaryl and Microcystis + carbaryl treatments (Table 1).

In all the experiments the age (AFR) and size (SFR) of daphnids at first reproduction were recorded. To determine the age at maturity, the females were checked for eggs daily. We measured body length of daphnids to the nearest $0.03 \mathrm{~mm}$ using a light microscope at $48 \times$ magnification and recorded the number of eggs. The offspring were counted right

Table 1 Concentrations of carbaryl and M. aeruginosa applied in experiments

\begin{tabular}{|c|c|c|c|c|c|c|c|c|c|c|c|c|c|c|c|c|}
\hline \multirow{2}{*}{\multicolumn{3}{|c|}{$\begin{array}{l}\text { Experiment } 1 \\
\text { Carbaryl }\end{array}$}} & \multirow{2}{*}{\multicolumn{3}{|c|}{$\frac{\text { Experiment } 2}{\text { Microcystis }}$}} & \multicolumn{11}{|c|}{ Experiment 3} \\
\hline & & & & & & \multicolumn{3}{|c|}{ Carbaryl } & \multicolumn{3}{|c|}{ Microcystis } & \multicolumn{5}{|c|}{ Carbaryl + Microcystis } \\
\hline & $\mu \mathrm{g} 1^{-1}$ & SD & & $\%$ & Cells $\mathrm{ml}^{-1}$ & & $\mu \mathrm{g} 1^{-1}$ & SD & & $\%$ & Cells $\mathrm{ml}^{-1}$ & & $\mu \mathrm{g} 1^{-1}$ & SD & $\%$ & Cells $\mathrm{ml}^{-1}$ \\
\hline P1 & 0.66 & 0.01 & M1 & 3 & 11,250 & $\mathrm{P} 1$ & 1.61 & 0.05 & M1 & 1.5 & 5,625 & MP1 & 1.61 & 0.05 & 1.5 & 5,625 \\
\hline $\mathrm{P} 2$ & 1.20 & 0.08 & M2 & 5 & 18,750 & $\mathrm{P} 2$ & 2.31 & 0.05 & M2 & 3 & 11,250 & MP2 & 2.31 & 0.05 & 3 & 11,250 \\
\hline P3 & 2.34 & 0.09 & M3 & 10 & 37,500 & P3 & 4.00 & 0.08 & M3 & 7.5 & 28,125 & MP3 & 4.00 & 0.08 & 7.5 & 28,125 \\
\hline P4 & 3.96 & 0.10 & M4 & 15 & 56,250 & P4 & 6.22 & 0.24 & M4 & 10 & 37,500 & MP4 & 6.22 & 0.24 & 10 & 37,500 \\
\hline P5 & 5.28 & 0.46 & M5 & 20 & 75,000 & P5 & 8.76 & 0.14 & M5 & 15 & 56,250 & MP5 & 8.76 & 0.14 & 15 & 56,250 \\
\hline
\end{tabular}

P1-P5: carbaryl levels, M1-M5: Microcystis levels, MP1-MP5: Microcystis + carbaryl levels, \%: percent of the Microcystis cells in the total food particles concentration (Microcystis + Scenedesmus) 
after the birth and moved for further observations to separate containers with clean media and food.

\section{Statistical analyses}

Statistical analyses were carried out with the STATISTICA data analysis software system (StatSoft, Inc., 2007, version 8.0. www.statsoft.com). The data from experiment (1) with carbaryl only were log transformed to achieve homogeneity of variances and analyzed using one-way ANOVA. Experiment (2) with Microcystis only was analyzed with simple linear regression and experiment (3) with both factors included was analyzed using factorial regression. The actual measured concentrations of microcystin in daphnids' body were used for factorial regression analyses. Regression was used instead of ANOVA because concentrations of microcystins found in daphnids' bodies did not represent the levels of treatments, e.g., microcystin concentration in Daphnia from the treatment M1 could be higher than from the M2.

\section{Results}

Experiment 1: carbaryl

Carbaryl caused significant delays in maturity of D. pulicaria (AFR: $F=3.248 ; P=0.018$ ) (Fig. 1A). However, daphnids matured later only in the treatment P1 with carbaryl concentration of $1.61 \mu \mathrm{g} \mathrm{l}^{-1}$ (HSD post hoc; $P=0.03$ ), while the individuals exposed to concentrations from 2.31 up to $8.76 \mu \mathrm{g} 1^{-1}$ matured at a similar time as those in the controls. A stimulating effect of the lowest concentration of carbaryl on SFR was observed $(F=2.995 ; P=0.026)$, where daphnids grew larger than in the controls (Fig. 1B). Then SFR was decreasing with increasing carbaryl concentration and was significantly reduced in treatments $\mathrm{P} 4$ and P5. The number of eggs per female in the first clutch did not significantly differ $(F=0.2057$; $P=0.957$ ) (Fig. 1C), but the number of newborns in the first clutch was reduced due to high mortality $(F=5.5705 ; P=0.001)$. The strongest influence was observed at the lowest level of carbaryl (HSD post hoc; $P=0.043)$, where most of the newborns died (Fig. 1D).

\section{Experiment 2: microcystin}

Daphnids were exposed to five concentrations of M. aeruginosa $(3,5,10,15$, and $20 \%$ of the total food particles concentration) (Table 1). However, each individual of Daphnia accumulated microcystin LR inside its body and had a unique concentration value for which did not correspond to the treatment levels. Therefore, we used the actual concentrations of microcystins measured in Daphnia's body for further analysis instead of treatment levels. Increasing microcystin concentrations significantly delayed AFR $\left(P=0.0002, r^{2}=0.27\right)$ and reduced the $\operatorname{SFR}\left(P=0.00002, r^{2}=0.34\right)$ (Fig. 2A, B). Also the number of eggs and newborns in first clutch was significantly negatively correlated with microcystin content in mothers' body $\left(P=0.00004, r^{2}=0.31\right.$ and $P=0.00008, r^{2}=0.30$, respectively) (Fig. 2C). Moreover, high mortality among newborns was noticed (Fig. 2D).

Experiment 3: combined effects of microcystin and carbaryl

In the third experiment, combined effects of the stressors were tested. For all measured variables, microcystin had a significant negative effect on AFR $(F=24.573$; $P=0.000005)$, SFR $(F=7.651 ; P=0.007)$, number of eggs in the first clutch $(F=29.8470$; $P=0.000001)$, and number of newborns in the first clutch $(F=24.9508 ; P=0.000005)$ (Fig. 3). In contrast, the pesticide had no significant effect in any of the cases. However, a significant interaction was detected between microcystin and carbaryl, what caused Daphnia to mature later and at a smaller size; the AFR significantly increased $(F=4.096 ; P=0.000005)$ (Fig. 3A), while SFR was significantly reduced $(F=9.319 ; P=0.003)$ (Fig. $3 \mathrm{~B})$. There was also an interaction in the case of number of eggs $(F=6.6416$; $P=0.01$ ) (Fig. 3C). However, there was no significant interaction in the case of number of newborns, but it should be noticed that the mortality of newborns was high and in many cases reached $100 \%$ of the clutch. We also observed that many newborns, released from the brood chamber were undeveloped, not fully swimming and hair or tail spines not being in straight position. Moreover, we observed body deformations (dented dorsal parts of body, not fully rejected molt, and reduced size of the heart). In general, these offspring could not swim properly and died within $4 \mathrm{~h}$. 
Fig. 1 Results of Experiment 1 with Daphnia pulicaria exposed to carbaryl only. Carbaryl concentrations at different treatment levels were: $\mathrm{C} \quad($ control $)=0.00 \mu \mathrm{g} \mathrm{1^{-1 }} ; \mathrm{P} 1=$ $1.61 \mu \mathrm{g}^{-1} ; \quad \mathrm{P} 2=2.31 \mu \mathrm{g}^{-1} ; \quad \mathrm{P} 3=4.00 \mu \mathrm{g}^{-1} ; \quad \mathrm{P} 4=$ $6.22 \mu \mathrm{g}^{-1}$; and P5 $=8.76 \mu \mathrm{g}^{-1}$. A Age at first reproduction; $\mathbf{B}$ size at first reproduction; $\mathbf{C}$ number of eggs per female in the first clutch; and $\mathbf{D}$ number of newborns per female in the first clutch. Squares represent means and whiskers standard errors

\section{Discussion}

The results presented here show that there is strong and significant interaction between the natural stressor microcystin (toxin in the cyanobacterium Microcystis) and the man-made toxicant carbaryl. Even the shortterm exposure to the sub-lethal doses of the pesticide can potentiate the effects when daphnids are exposed to microcystin for long term. D. pulicaria confronted simultaneously with cyanotoxin and pesticide, appears to delay reproduction, mature at a smaller size and have less offspring than individuals treated with only a single stressor. For SFR the joint effect appears to be even synergistic, as for the effect on newborns. Body deformations and molting problems in offspring are observed only in treatments with both stressors present. Rohrlack et al. (2004) identified microviridin J as the source of a fatal molting disruption in D. pulicaria feeding on Microcystis cells. We have found no evidence of it in the experiment with Microcystis cells only, but we did find this in the experiment with both stressors present. Main mode of action of carbaryl involves inhibition of the nerve enzyme cholinesterase and consequential disruption of the nervous system. It is also considered to be an endocrine disruptor (EPA, 2005). It is likely that Microcystis enhances the negative influence of carbaryl on Daphnia. Possibly, carbaryl influences the endocrine or nervous system of mothers, and microcystin prevents the recovery after exposure to carbaryl. There are examples of interactions between carbaryl and natural chemicals that caused various morphological disabilities. Sakamoto et al. (2006) in their experiment showed that Bosmina changed its morphology in response to the kairomone, but development was inhibited by carbaryl at a sublethal concentration even in the presence of the kairomone. Also Hanazato \& Dodson (1993) reported carbaryl to cause morphological changes in various Daphnia species; by stimulating the nervous system carbaryl induced the morphological changes, which
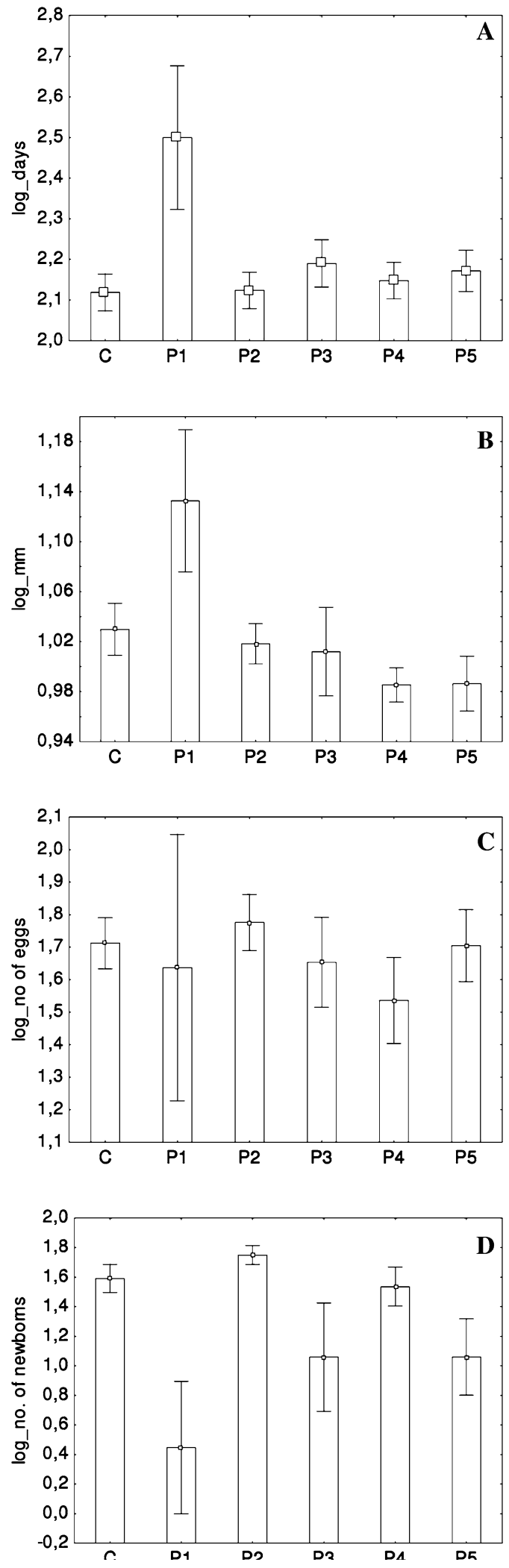
Fig. 2 Results of Experiment 2 Daphnia pulicaria exposed to microcystis LR within cells of M. aeruginosa. The Microcystis concentrations (expressed as percent of total amount of food particles) in experiment (2) consisted of $\mathrm{C}$ (control) $=0.0 \%$; $\mathrm{M} 1=3.0 \% ; \quad \mathrm{M} 2=5 \% ; \quad \mathrm{M} 3=10 \% ; \quad \mathrm{M} 4=15 \%, \quad$ and M5 $=20 \%$. The $X$ axis represents the actual values of microcystin concentrations within bodies of individual daphnids. A Age at first reproduction; B size at first reproduction; $\mathbf{C}$ number of eggs per female in the first clutch; and $\mathbf{D}$ number of newborns per female in the first clutch

originally evolved as a response to predator kairomone. Synergistics effects for carbaryl and the parasite Pasteuria ramosa that reduce the survival significantly in D. magna have also been on record (Coors \& De Meester, 2008). According to these authors immunomodulatory activity of carbaryl appears to lead to an impairment of the immune response that is important to cope with parasite infection. However, the body deformations and molting problems in offspring can be also explained by size-dependent toxicity, where embryos and first instars are the most sensitive to chemical stress (Enserink et al., 1990; Hanazato, 1991). It is possible that additional stressor, the pesticide, lowers the threshold where Daphnia can defend against cyanotoxin.

In the first experiment, carbaryl at the lowest concentration stimulated the daphnids to grow larger. They reached maturation at larger size than controls or daphnids in other carbaryl concentrations. This result was unexpected, but may be an hormetic effect. Forbes (2000) defines hormesis as stimulatory effects occurring in response to low levels of exposure to agents that are harmful at high levels of exposure. One of the hypotheses discussed in Forbes' article is that occurrence of hormesis for individual life-history traits can be explained as an evolutionary adaptation that acts to maintain fitness in a changing environment. The larger size at first reproduction at a low level of carbaryl found in our study could be a good example of such an adaptation, since larger sized daphnids are better prepared to stressors (Gustafsson et al., 2005). However, not all traits are likely to exhibit hormesis simultaneously, and therefore overall fitness is not likely to be enhanced at low levels of exposure to toxic agents (Forbes, 2000). The daphnids in our experiment with carbaryl had larger size at maturation but they matured later and mortality of newborns increased comparing to controls and treatments with higher concentrations of carbaryl.
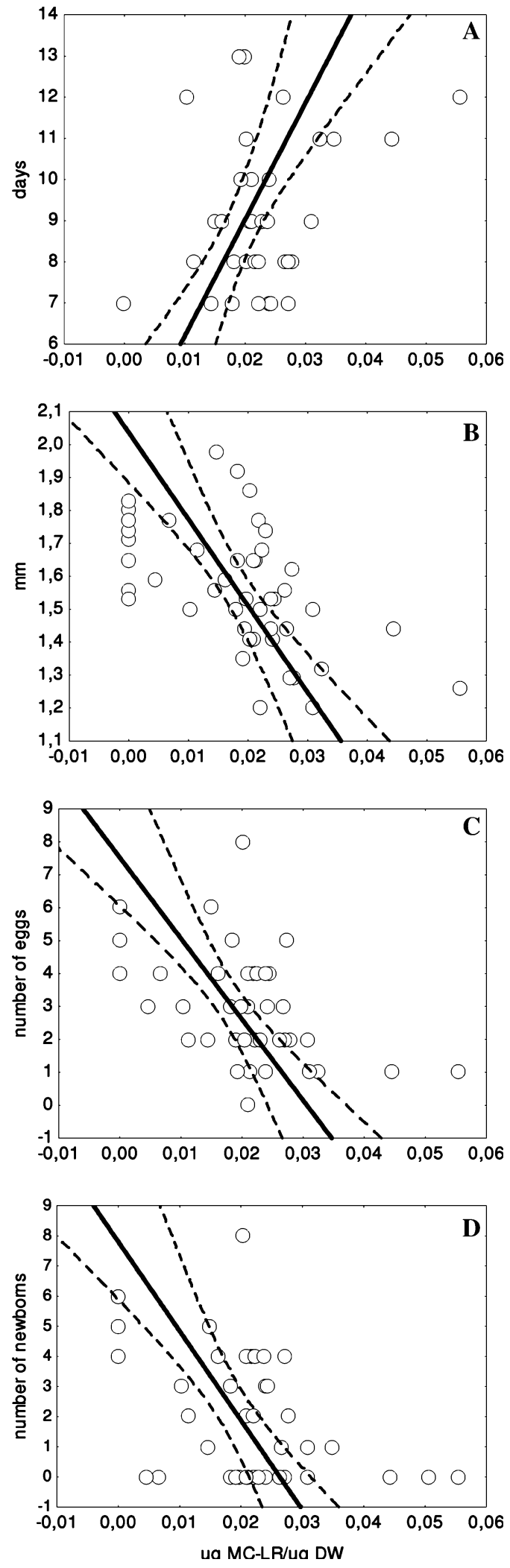
Fig. 3 Results of Experiment 3 with Daphnia pulicaria exposed to both $M$. aeruginosa and carbaryl together. Carbaryl concentrations at different treatment levels were: $\mathrm{C}$ (control $)=0.00 \mu \mathrm{g} \mathrm{l}^{-1} ; \quad \mathrm{P} 1=1.61 \mu \mathrm{g} \mathrm{l}^{-1} ; \quad \mathrm{P} 2=2.31 \mu \mathrm{g} \mathrm{l}^{-1}$; $\mathrm{P} 3=4.00 \mu \mathrm{g} \mathrm{l}^{-1}$; and $\mathrm{P} 4=6.22 \mu \mathrm{g} \mathrm{l}^{-1}$. The $X$ axis represents the actual values of microcystin concentrations in individual daphnids. A Age at first reproduction; B size at first reproduction; $\mathbf{C}$ number of eggs per female in the first clutch; and D number of newborns per female in the first clutch. Carbaryl only is represented by the solid lines, Microcystis only is represented by the dotted line and both factors acting simultaneously are depicted by the broken line

There are only a few studies dealing with microcystin content in daphnids and many of them report the average contents of microcystins in a group of individuals from a clone (e.g., Thostrup \& Christoffersen, 1999) or the whole zooplankton community (Watanabe et al., 1992). In our study, we analyzed microcystin content extracting single individuals and found actual concentrations of microcystins within the daphnid's body. These did not represent the nominal values of various Microcystis treatments. It is likely that due to low Microcystis cell numbers and high proportion of Scenedesmus daphnids are able to maintain the toxin level at a point which is still tolerable. It seems that the maximum for microcystin accumulated in the body of an individual Daphnia depends not only on its condition and size, but also on food quality (Hietala et al., 1997). We found that microcystin can accumulate in daphnids and that there is a negative correlation between accumulated microcystins and body length of Daphnia which is in agreement with (Thostrup \& Christoffersen, 1999). Also Ferrão-Filho et al. (2002) found that zooplankton is an efficient accumulator of microcystins.

It is concluded that the cyanotoxin and the pesticide potentiate when combined. These effects are mostly additive but some, like body deformations of newborns, are more severe than predicted. This very negative interaction between cyanotoxins and pesticides was not shown before. Moreover, our results show that several life-history parameters of individuals exposed for a long time to toxic cyanobacteria can be strongly negatively influenced by low sub-lethal concentrations of the pesticide, even if the period of exposure is very short (pulse exposure for $24 \mathrm{~h}$ ). Carbaryl at the lowest concentration stimulates the daphnids to grow larger. However, this stimulation is at a cost of longer
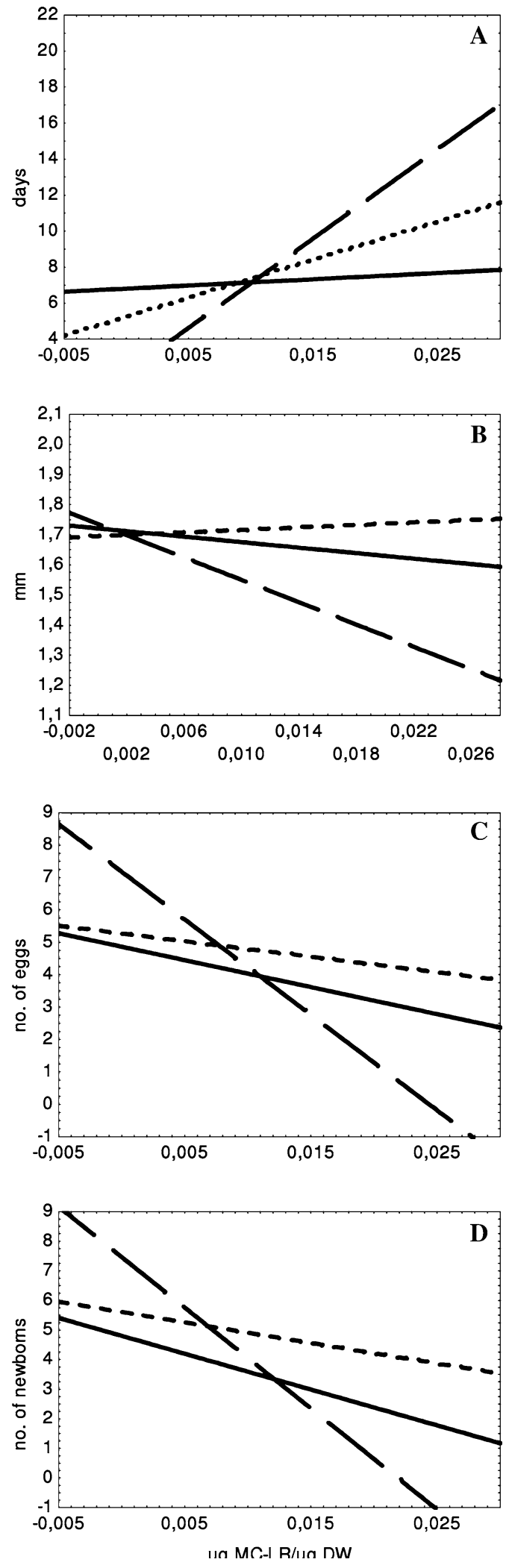
maturation time and fewer offspring and cannot be considered as an evolutionary adaptation to maintain fitness.

Acknowledgments This study was supported by a Marie Curie EIF grant "Multistress" no. 40971 funded by the European Commission. The authors would like to thank Dr Ramesh D. Gulati for his valuable comments that improved this manuscript. We would also like to thank Koos (J.) Vijverberg, Frans van der Wielen, Nico Helmsing, Suzanne Wiezer, and Dedmer van de Waal for their help and advice on every step of this work.

Open Access This article is distributed under the terms of the Creative Commons Attribution Noncommercial License which permits any noncommercial use, distribution, and reproduction in any medium, provided the original author(s) and source are credited.

\section{References}

Chorus, I. \& J. Bartram, 1999. Toxic Cyanobacteria in Water: A Guide to Their Public Health Consequences, Monitoring and Management. E and FN Spon, London.

Coors, A. \& L. De Meester, 2008. Synergistic, antagonistic and additive effects of multiple stressors: predation threat, parasitism and pesticide exposure in Daphnia magna. Journal of Applied Ecology 45: 1820-1828.

DeMott, W. R., Q. X. Zhang \& W. W. Carmichael, 1991. Effects of toxic cyanobacteria and purified toxins on the survival and feeding of a copepod and 3 species of Daphnia. Limnology and Oceanography 36: 1346-1357.

Doksaeter, A. \& J. Vijverberg, 2001. The effects of food and temperature regimes on life-history responses to fish kairomones in Daphnia hyalina $\mathrm{x}$ galeata. Hydrobiologia 442: 207-214.

Enserink, L., W. Luttmer \& H. Maasdiepeveen, 1990. Reproductive strategy of Daphnia magna affects the sensitivity of its progeny in acute toxicity tests. Aquatic Toxicology 17: $15-26$.

EPA. Science Policy Council. 2005. Handbook for Non-Cancer Health Effects Valuation. Appendix C: Case Studies. Economic Valuation of Endocrine Disruption: Introduction. www.epa.gov/osa/spc/htm/Endoqs.htm.

Fastner, J., I. Flieger \& U. Neumann, 1998. Optimised extraction of microcystins from field samples - a comparison of different solvents and procedures. Water Research 32: 3177-3181.

Ferrão-Filho, A. D. S., B. Kozlowsky-Suzuki \& S. M. F. O. Azevedo, 2002. Accumulation of microcystins by a tropical zooplankton community. Aquatic Toxicology 59: 201-208.

Forbes, V. E., 2000. Is hormesis an evolutionary expectation? Functional Ecology 14: 12-24.

Guillard, R. R. L. \& C. J. Lorenzen, 1972. Yellow-green algae with chlorophyllide c. Journal of Phycology 8: 4.

Gustafsson, S., K. Rengefors \& L. A. Hansson, 2005. Increased consumer fitness following transfer of toxin tolerance to offspring via maternal effects. Ecology 86: 2561-2567.
Hanazato, T., 1991. Effects of a chaoborus-released chemical on Daphnia ambigua: reduction in the tolerance of the Daphnia to summer water temperature. Limnology and Oceanography 36: 165-171.

Hanazato, T. \& S. I. Dodson, 1993. Morphological responses of four species of cyclomorphic Daphnia to a short-term exposure to the insecticide carbaryl. Journal of Plankton Research 15: 1087-1095.

Hanazato, T. \& S. I. Dodson, 1995. Synergistic effects of low oxygen concentration, predator kairomone, and a pesticide on the cladoceran Daphnia pulex. Limnology and Oceanography 40: 700-709.

Havens, K. E., 1995. Insecticide (carbaryl, 1-napthyl-n-methyl carbamate) effects on a fresh-water plankton community zooplankton size, biomass, and algal abundance. Water Air and Soil Pollution 84: 1-10.

Helgen, J. C., N. J. Larson \& R. L. Anderson, 1988. Responses of zooplankton and chaoborus to temephos in a natural pond and in the laboratory. Archives of Environmental Contamination and Toxicology 17: 459-471.

Hietala, J., C. Lauren-Maatta \& M. Walls, 1997. Life history responses of Daphnia clones to toxic Microcystis at different food levels. Journal of Plankton Research 19: 917-926.

Hulsmann, S., J. Vijverberg, M. Boersma \& W. M. Mooij, 2004. Effects of infochemicals released by gape-limited fish on life history traits of Daphnia: a maladaptive response? Journal of Plankton Research 26: 535-543.

Kluttgen, B., U. Dulmer, M. Engels \& H. T. Ratte, 1994. $\mathrm{ADaM}$, an artificial fresh-water for the culture of zooplankton. Water Research 28: 743-746.

Liess, M., R. Schulz, M. H. D. Liess, B. Rother \& R. Kreuzig, 1999. Determination of insecticide contamination in agricultural headwater streams. Water Research 33: 239-247.

Lürling, M., 2003. Effects of microcystin-free and Microcystin containing strains of the cyanobacterium Microcystis aeruginosa on growth of the grazer Daphnia magna. Environmental Toxicology 18: 202-210.

Paerl, H. W. \& J. Huisman, 2008. Blooms like it hot. Science 320: 57-58.

Rohrlack, T., K. Christoffersen, M. Kaebernick \& B. A. Neilan, 2004. Cyanobacterial protease inhibitor microviridin J causes a lethal molting disruption in Daphnia pulicaria. Applied and Environmental Microbiology 70: 5047-5050.

Sakamoto, M., K. H. Chang \& T. Hanazato, 2006. Inhibition of development of anti-predator morphology in the small cladoceran Bosmina by an insecticide: impact of an anthropogenic chemical on prey-predator interactions. Freshwater Biology 51: 1974-1983.

Sih, A., G. Englund \& D. Wooster, 1998. Emergent impacts of multiple predators on prey. Trends in Ecology \& Evolution 13: 350-355.

Sivonen, K. \& G. Jones, 1999. Cyanobacterial toxins. In Chorus, I. \& J. Bartram (eds), Toxic Cyanobacteria: A Guide to Public Health Consequences and their Management in Water Resources and Supplies. WHO, E\&FN Spon, London: 41-111.

Sondergaard, M. \& E. Jeppesen, 2007. Anthropogenic impacts on lake and stream ecosystems, and approaches to restoration. Journal of Applied Ecology 44: 1089-1094. 
Thostrup, L. \& K. Christoffersen, 1999. Accumulation of microcystin in Daphnia magna feeding on toxic microcystis. Archiv Fur Hydrobiologie 145: 447-467.

Tonk, L., P. M. Visser, G. Christiansen, E. Dittmann, E. Snelder, C. Wiedner, L. R. Mur \& J. Huisman, 2005. The microcystin composition of the cyanobacterium Planktothrix agardhii changes toward a more toxic variant with increasing light intensity. Applied and Environmental Microbiology 71: 5177-5181.

Tonk, L., M. Welker, J. Huisman \& P. M. Visser, 2009. Production of cyanopeptolins, anabaenopeptins, and microcystins by the harmful cyanobacteria Anabaena 90 and Microcystis PCC 7806. Harmful Algae 8: 219-224.
Vinebrooke, D., L. Cottingham, M. S. Norberg, I. Dodson, C. Maberly \& U. Sommer, 2004. Impacts of multiple stressors on biodiversity and ecosystem functioning: the role of species co-tolerance. Oikos 104: 451-457.

Von Elert, E., 2004. Food quality constraints in Daphnia: interspecific differences in the response to the absence of a long chain polyunsaturated fatty acid in the food source. Hydrobiologia V526: 187-196.

Watanabe, M. M., K. Kaya \& N. Takamura, 1992. Fate of the toxic cyclic heptapeptides, the microcystins, from blooms of Microcystis (Cyanobacteria) in a hypertrophic lake. Journal of Phycology 28: 761-767 